\title{
Influence of oxygen on NADH recycling and oxidative stress resistance systems in Lactobacillus panis PM1
}

\author{
Tae Sun Kang, Darren R Korber and Takuji Tanaka*
}

\begin{abstract}
Lactobacillus panis strain PM1 is an obligatory heterofermentative and aerotolerant microorganism that also produces 1,3-propanediol from glycerol. This study investigated the metabolic responses of L. panis PM1 to oxidative stress under aerobic conditions. Growth under aerobic culture triggered an early entrance of L. panis PM1 into the stationary phase along with marked changes in end-product profiles. A ten-fold higher concentration of hydrogen peroxide was accumulated during aerobic culture compared to microaerobic culture. This $\mathrm{H}_{2} \mathrm{O}_{2}$ level was sufficient for the complete inhibition of L. panis PM1 cell growth, along with a significant reduction in end-products typically found during anaerobic growth. In silico analysis revealed that L. panis possessed two genes for NADH oxidase and NADH peroxidase, but their expression levels were not significantly affected by the presence of oxygen. Specific activities for these two enzymes were observed in crude extracts from L. panis PM1. Enzyme assays demonstrated that the majority of the $\mathrm{H}_{2} \mathrm{O}_{2}$ in the culture media was the product of $\mathrm{NADH}: \mathrm{H}_{2} \mathrm{O}_{2}$ oxidase which was constitutively-active under both aerobic and microaerobic conditions; whereas, NADH peroxidase was positively-activated by the presence of oxygen and had a long induction time in contrast to NADH oxidase. These observations indicated that a coupled NADH oxidase - NADH peroxidase system was the main oxidative stress resistance mechanism in L. panis PM1, and was regulated by oxygen availability. Under aerobic conditions, $\mathrm{NADH}$ is mainly reoxidized by the NADH oxidase - peroxidase system rather than through the production of ethanol (or 1,3-propanediol or succinic acid production if glycerol or citric acid is available). This system helped L. panis PM1 directly use oxygen in its energy metabolism by producing extra ATP in contrast to homofermentative lactobacilli.
\end{abstract}

Keywords: Lactobacillus panis, NADH oxidase, NADH peroxidase, Electron acceptor, Hydrogen peroxide

\section{Introduction}

Lactobacillus panis PM1 is an aerotolerant and obligatory heterofermentative microorganism isolated from bioethanol thin stillage, and has been the focus of attention due to its ability to produce 1,3-propanediol (1,3-PDO) during the fermentation of glycerol under anaerobic conditions (Khan et al. 2013). Lactobacillus panis belongs to the group III heterofermentative lactobacilli, which includes $L$. brevis, L. buchneri and L. reuteri, where the 6-phosphogluconate/phosphoketolase (6-PG/

\footnotetext{
*Correspondence: Takuji.tanaka@usask.ca

Department of Food and Bioproduct Sciences, College of Agriculture and Bioresources, University of Saskatchewan, 51 Campus Drive, Saskatoon, SK S7N 5A8, Canada
}

PK) pathway is the primary carbohydrate fermentation pathway (Khan et al. 2013; Luthi-Peng et al. 2002; Pedersen et al. 2004; Veiga-da-Cunha and Foster 1992). In theory, when one glucose molecule is consumed, three $\mathrm{NADH}$ and one ATP molecules are generated. Subsequently, one pyruvic acid and one acetyl phosphate molecules accept protons from one and two NADH molecules, respectively, and regenerate $\mathrm{NAD}^{+}$. End-products of this metabolism are lactic acid and ethanol, respectively. Overall heterolactic fermentation of glucose through the 6-PG/PK pathway results in $1 \mathrm{~mol}$ each of lactic acid, ethanol, and $\mathrm{CO}_{2}$ and 1 mol ATP per mol glucose consumed (Kandler 1983).

For heterofermentative lactic acid bacteria (LAB), external electron acceptors can be used as alternate routes to

\section{穴}

(c) 2013 Kang et al.; licensee Springer. This is an Open Access article distributed under the terms of the Creative Commons Attribution License (http://creativecommons.org/licenses/by/2.0), which permits unrestricted use, distribution, and reproduction in any medium, provided the original work is properly cited. 
reproduce $\mathrm{NAD}^{+}$. The presence or absence of electron acceptors determine whether ethanol (and no more ATP) or acetic acid (and 1 additional ATP) is produced from a glucose molecule (Chen and McFeeters 1986; Condon 1987; McFeeters and Chen 1986; Talarico et al. 1990; Veiga-da-Cunha and Foster 1992). For example, when glycerol exists, the regeneration of $\mathrm{NAD}^{+}$for glucose metabolism can be achieved through the conversion of glycerol to 1,3-PDO using glycerol as the electron receptor (Saxena et al. 2009; Veiga-da-Cunha and Foster 1992). The presence of external electron acceptors, therefore, affects the energy metabolism and end-product profiles, as well as further fermentation applications of LAB.

Molecular oxygen can act as an external electron acceptor and can be advantageous to LAB during cell growth, and its presence in culture conditions greatly influences the physiology of many LAB (An et al. 2010; Condon 1987; Higuchi et al. 2000; Marty-Teysset et al. 2000; Miyoshi et al. 2003). While oxygen itself is not toxic, reactive oxygen species (ROS; including the superoxide anion radical $\left(\mathrm{O}_{2}^{-}\right)$, the hydroxyl radical $\left({ }^{\circ} \mathrm{OH}\right)$, and hydrogen peroxide $\left.\left(\mathrm{H}_{2} \mathrm{O}_{2}\right)\right)$ which are produced during cellular processes can cause a variety of damage to the cell (Condon 1987; Higuchi et al. 2000; Miyoshi et al. 2003). Unlike aerobes and facultative anaerobes, such as Escherichia coli and Salmonella typhimurium, that have evolved efficient mechanisms for protection against ROS (Farr and Kogoma 1991), LAB lack catalases and functional cytochrome oxidases required for energy-linked oxygen metabolism (An et al. 2011; An et al. 2010; Jansch et al. 2011). Some LAB possess oxidases that utilize molecular oxygen to oxidize substrates such pyruvate or NADH (Condon 1987; Marty-Teysset et al. 2000; Sedewitz et al. 1984). Generally, NADH oxidase is the most common oxidative enzyme in LAB and the systems are often oxygen-inducible (Condon 1987; Higuchi et al. 2000; Komagata 1996; Miyoshi et al. 2003). However, the activity of NADH oxidase can produce hydrogen peroxide $\left(\mathrm{H}_{2} \mathrm{O}_{2}\right)$ which can then directly oxidize protein cysteinyl residues and inactivate enzymes (Miyoshi et al. 2003). Hydrogen peroxide can also react with cations, such as $\mathrm{Fe}^{2+}$ and $\mathrm{Cu}^{2+}$, giving rise to hydroxyl radicals via the Fenton reaction (Miyoshi et al. 2003).

Therefore, the presence of oxygen in the growth environment of LAB will induce oxidative stress to which bacteria have various responses mechanisms. A common oxidative stress resistance mechanism found in LAB is a coupled NADH oxidase - NADH peroxidase system (Miyoshi et al. 2003). In these coupled reactions, intracellular oxygen is first used to oxidize $\mathrm{NADH}$ into $\mathrm{NAD}^{+}$by $\mathrm{NADH}$ oxidase, thereby releasing $\mathrm{H}_{2} \mathrm{O}_{2}$. Subsequently, $\mathrm{H}_{2} \mathrm{O}_{2}$ is reduced to $\mathrm{H}_{2} \mathrm{O}$ by NADH peroxidase (Condon 1987; Higuchi et al. 2000; Miyoshi et al. 2003). However, the activity of NADH peroxidase is generally low (10 to 30 times lower than that of NADH oxidase) in L. lactis and has not been detected in some latobacillus strains. Thus, cellular $\mathrm{H}_{2} \mathrm{O}_{2}$ detoxification is inefficient in some $\mathrm{LAB}$ capable of producing $\mathrm{H}_{2} \mathrm{O}_{2}$ under aerobic conditions (Anders et al. 1970; Komagata 1996).

Our previous research showed that the presence of oxygen during the fermentation of glycerol by $L$. panis PM1 negatively affected cell growth, glucose consumption, and end-product production, including 1,3-PDO. The protection mechanism towards oxidative stress is a key element to optimize L. panis PM1 for 1,3-PDO production in biofuel waste material applications. The NADH oxidase - NADH peroxidase system and conversion of glycerol to 1,3-PDO both use NADH as a key factor for their reactions. Therefore, the clarification of the control of oxidative stress by this strain can shed light on how it regulates 1,3-PDO production. In this study, we clearly demonstrated the oxygen-dependent function of NADH oxidase and NADH peroxidase and its involvement in the $\mathrm{NAD}^{+}$regeneration system of L. panis PM1.

\section{Materials and methods Chemicals}

All chemicals used in this study were ACS grade, or better, and purchased from Sigma-Aldrich (St. Louis, MO, USA).

\section{Bacterial strains and growth conditions}

Lactobacillus panis PM1 was isolated from bioethanol thin stillage in our lab (International Depository Authority of Canada; accession number 180310-01). Strain PM1 was cultured at $37^{\circ} \mathrm{C}$ using commercial MRS medium (BD, Franklin Lakes, NJ, USA) until late log phase and was then transferred to modified MRS medium (mMRS). The mMRS medium consisted of $10 \mathrm{~g}$ glucose, $5 \mathrm{~g}$ yeast extract, $10 \mathrm{~g}$ peptone, $10 \mathrm{~g}$ meat extract, $2 \mathrm{~g} \mathrm{~K}_{2} \mathrm{HPO}_{4}$, $2 \mathrm{~g}$ ammonium citrate, $5 \mathrm{~g}$ sodium acetate, $100 \mathrm{mg}$ $\mathrm{MgSO}_{4} \cdot 7 \mathrm{H}_{2} \mathrm{O}, 50 \mathrm{mg} \mathrm{MnSO}_{4}$, along with a defined concentration of electron acceptors, such as citric acid $(26 \mathrm{mM})$ or glycerol $(160 \mathrm{mM})$ per litre. The cultures were incubated at $37^{\circ} \mathrm{C}$ under aerobic or microaerobic conditions. Aerobic and microaerobic cultures were grown using the same medium and temperature. Continuous aeration was provided to aerobic cultures by agitation; whereas, air-tight $15 \mathrm{ml}$ tubes, filled to the two-thirds level, were incubated under static conditions to establish microaerobic conditions. It should be noted that our previous study (Khan et al. 2013) indicated there was little difference in the behaviour of L. panis PM1 under anaerobic and microaerobic conditions, thus we did not include anaerobic culture in this study.

\section{Quantification of $\mathrm{H}_{2} \mathrm{O}_{2}$ production}

Lactobacillus panis PM1 cells were removed from the culture media using centrifugation $(14,000 \times g, 5 \mathrm{~min})$. Hydrogen peroxide concentrations of the cell-free media 
were measured in accordance with the Pierce Quantitative Peroxide Assay Kit (Thermo Scientific, Rockford, IL, USA) based on oxidation of ferrous to ferric ion in the presence of xylenol orange.

\section{RNA preparation}

RNA was extracted from Lactobacillus panis PM1 cells by the hot phenol extraction method, as described by $\mathrm{Oh}$ and So (2003) with minor modifications. Briefly, $10 \mathrm{ml}$ of exponentially-growing bacteria from liquid media were added to a tube containing $1.25 \mathrm{ml}$ of ice-cold ethanol/ phenol stop solution ( $5 \%$ water-saturated phenol, $\mathrm{pH}<4.5$, in $95 \%$ ethanol), and harvested by centrifugation for $5 \mathrm{~min}$ at $10,000 \mathrm{x}$ g. The cell pellets were resuspended in $600 \mu \mathrm{l}$ of diethylpyrocarbonate (DEPC)-treated water. Glass beads (0.8 g, 452-600 $\mu \mathrm{m}$ in diameter; Sigma) and $600 \mu \mathrm{l}$ of prewarmed acid-hot phenol:chloroform:isoamylacohol (PCI, $25: 24: 1, \mathrm{v} / \mathrm{v}$ ) were added to the cell suspensions, and the mixture was incubated at $65^{\circ} \mathrm{C}$ for $10 \mathrm{~min}$ with vigorous vortexing for $30 \mathrm{sec}$ duration every $30 \mathrm{sec}$. The samples were centrifuged for $10 \mathrm{~min}$ at $14,000 \mathrm{x} \mathrm{g}$ and then the supernatants $(500 \mu \mathrm{l})$ were transferred to fresh $1.5-\mathrm{ml}$ micro-tubes containing $500 \mu \mathrm{l}$ of the pre-warmed PCI and incubated at $65^{\circ} \mathrm{C}$ for $5 \mathrm{~min}$ with vortexing every $30 \mathrm{sec}$. Samples were then centrifuged for $10 \mathrm{~min}$ at $14,000 \mathrm{x} \mathrm{g}$. The aqueous layer $(400 \mu \mathrm{l})$ was transferred into new $1.5-\mathrm{ml}$ micro-tubes and mixed with $95 \%$ ethanol $(800 \mu \mathrm{l})$ and $3 \mathrm{M}$ sodium acetate $(40 \mu \mathrm{l})$. The mixtures were kept at $-80^{\circ} \mathrm{C}$ for $30 \mathrm{~min}$ and centrifuged at $14,000 \mathrm{x}$. The RNA pellet was washed with $70 \%$ ethanol and resuspended in $50 \mu \mathrm{l}$ of RNase-free water. RNA was treated with DNase and purified using the RNeasy kit (Qiagen, Toronto, ON, Canada). The quantity of RNA was determined by measuring the absorbance at $260 \mathrm{~nm}$ (optical density (OD) 1 at $\mathrm{A}_{260}=40 \mu \mathrm{g}$. $\mathrm{ml}^{-1}$ RNA), using a DU 800 spectrophotometer (Beckman Coulter, Mississauga, ON, Canada), and its purity was determined by measuring the $\mathrm{A}_{260} / \mathrm{A}_{280}$ ratio.

\section{Reverse transcription}

The primers used in this study were specifically designed by Primer3 (http://frodo.wi.mit.edu/primer3/) for real

Table 1 Sequences of primers used for qRT_PCR in this study

\begin{tabular}{ccccc}
\hline $\begin{array}{c}\text { Target } \\
\text { gene }\end{array}$ & Function & Primer & $\mathbf{T m}\left({ }^{\circ} \mathbf{C}\right)$ & $\begin{array}{c}\text { Nucleotide sequence } \\
\left(\mathbf{5}^{\prime} \rightarrow \mathbf{3}^{\prime}\right)\end{array}$ \\
\hline 16S rRNA & 165 & f16S & 58 & tggcccaactgatatgac \\
& $\begin{array}{c}\text { ribosomal } \\
\text { RNA }\end{array}$ & r16S & 58 & ctctcatgcacgttcttctt \\
nox & NADH & fNOX & 60 & actggggctgagaagacaga \\
& oxidase & rNOX & 60 & tgctcatcaaaggcagtgac \\
$n p x$ & NADH & fNPX & 60 & tcatcaggtgtaacgccaaa \\
& peroxidase & rNPX & 60 & taacgcccatcttcaagtcc \\
\hline
\end{tabular}

time RT-PCR applications of L. panis PM1 from the nucleotide sequence of the annotation data (Table 1). The RT reaction mixture contained $0.5 \mu \mathrm{g}$ of total RNA and $0.25 \mu \mathrm{M}$ of reverse primers of the selected genes. The RT reaction was performed using qScript cDNA SuperMix (Quanta Biosciences, Inc., Gaithersburg, MD, USA) according to the manufacturer's instructions. The reaction mixture was incubated at $25^{\circ} \mathrm{C}$ for $5 \mathrm{~min}$ and at $42^{\circ} \mathrm{C}$ for $30 \mathrm{~min}$, and the reaction was terminated by incubation at $85^{\circ} \mathrm{C}$ for $5 \mathrm{~min}$ with a Techne thermal cycler (FTGENE5D, Techgene, Burlington, NJ, USA).

\section{Quantitative PCR}

Real-time PCR amplification was performed in a CFX96 real-time detection system (Bio-Rad, Hercules, CA, USA) using SsoFast EvaGreen Supermix (Bio-Rad). The total volume of the PCR master mixture was $20 \mu \mathrm{l}$, to which cDNA template equivalent to $25 \mathrm{ng}$ RNA starting material and $0.5 \mu \mathrm{M}$ of each primer (Table 1) was added. PCR amplification was initiated at $95^{\circ} \mathrm{C}$ for $30 \mathrm{~s}$ followed by 40 cycles of $95^{\circ} \mathrm{C}$ for $5 \mathrm{~s}$ and $60^{\circ} \mathrm{C}$ for $10 \mathrm{~s}$. Amplification was followed by a melt-curve analysis between $65^{\circ} \mathrm{C}$ and $95^{\circ} \mathrm{C}$ using a $0.5^{\circ} \mathrm{C}$ increment. All sample and primer combinations were assessed in three biological replicates with two technical replicates per biological replicate. A no-template control was used for the negative control PCR, and PCR specificity and product detection were verified by examining the temperature-dependent melting curves of the PCR products and ethidium bromide staining on 1\% agarose gel. For relative gene expression, the $2^{-\Delta \Delta \mathrm{Ct}}$ method using the $16 \mathrm{~S}$ rRNA gene as the normalizer was performed as described by Livak and Schmittgen (2001). The steps for calculating the expression ratio are following:

$$
\begin{aligned}
\Delta \mathrm{Ct}_{(\text {test })}= & \mathrm{Ct}_{(\text {nox } \text { and } n p x, \text { test })} \\
& -\mathrm{Ct}_{(16 S \text { rNA, test })} \\
\Delta \mathrm{Ct}_{(\text {control })}= & \mathrm{Ct}_{(\text {nox } \text { and } n p x, \text { control })} \\
& -\mathrm{Ct}_{(16 S \text { rNA, control })} \\
\Delta \Delta \mathrm{Ct}= & \Delta \mathrm{Ct}_{(\text {test })}-\mathrm{Ct}_{(\text {control })}
\end{aligned}
$$

Normalized expression ratio of nox and $n p x_{(\text {test })}=$ $2^{-\Delta \Delta C t}$

The Real-Time data were processed using CFX Manager Software (Bio-Rad).

\section{Preparation of crude extracts}

Lactobacillus panis PM1 cells grown to mid-exponential phase under microaerobic or aerobic conditions were harvested by centrifugation, washed with $100 \mathrm{mM}$ phosphate buffer ( $\mathrm{pH}$ 7.0), and the cells in pellets were then disrupted using sonication (three times for $1 \mathrm{~min}$ with a 3 min rest interval at output level 2, Sonifier 450; Branson, CT, USA) using the same buffer. Crude extract was 
obtained by centrifugation for $10 \mathrm{~min}$ at $14,000 \mathrm{x} \mathrm{g}$, and protein concentration was determined using the Protein Assay Kit (Bio-Rad) with bovine serum albumin (BSA) as a standard.

\section{Enzyme assay}

$\mathrm{NADH}$ oxidase and $\mathrm{NADH}$ peroxidase activities were determined by measuring the $\mathrm{H}_{2} \mathrm{O}_{2}$ concentration generated and decomposed by the crude extracts, respectively. The assay mixture contained $200 \mu \mathrm{M}$ of the reduced form of nicotinamide adenine dinucleotide (NADH) and $20 \mu \mathrm{M}$ flavin adenine dinucleotide $\left(\mathrm{FAD}^{+}\right)$in $50 \mathrm{mM}$ phosphate buffer at $\mathrm{pH}$ 6.0. The assay was carried out at $30^{\circ} \mathrm{C}$ under aerated or microaerobic conditions. For the NADH peroxidase assay, hydrogen peroxide was added into the above assay mixture to an initial concentration of $30 \mu \mathrm{M}$. The concentrations of $\mathrm{H}_{2} \mathrm{O}_{2}$ generated or decomposed were quantified as described above. In these determinations, one unit of activity corresponds to the generation (for NADH oxidase) and decomposition (for $\mathrm{NADH}$ peroxidase) of one $\mu \mathrm{mol}$ of $\mathrm{H}_{2} \mathrm{O}_{2}$ in one minute.

\section{Determination of glucose and end-products}

Culture optical density was measured as an index of growth at $600 \mathrm{~nm}$ with a DU 800 spectrophotometer. After centrifugation, the supernatant was filtered through $0.22-\mu \mathrm{m}$ pore size filters and stored at $-20^{\circ} \mathrm{C}$ for HPLC analysis. To quantify the concentration of glucose, organic acids and ethanol, samples were analyzed on an organic acid column (HPX-87H; Bio-Rad) using an HPLC system equipped with a refractive index detector (RID G1362A, 1100 series; Agilent Technologies, Palo Alto, CA, USA). Operating conditions were determined by the method described in the column manual with minor modifications. Filtered culture medium $(40 \mu \mathrm{l})$ was loaded on the column and eluted with $5 \mathrm{mM}$ sulfuric acid at a flow rate of $0.6 \mathrm{ml} / \mathrm{min}$ at $55^{\circ} \mathrm{C}$ for $30 \mathrm{~min}$.

\section{Statistical analysis}

For growth experiments and determinations of $\mathrm{H}_{2} \mathrm{O}_{2}$ concentrations, data are presented as the mean values calculated from at least three independent experiments. For activities of NADH oxidase and NADH peroxidase, standard errors of the means from at least three independent experiments were also calculated and presented. Differences in culture and enzyme assay conditions with NADH oxidase or $\mathrm{NADH}$ peroxidase activity (unit/mg protein) were analyzed by the $t$ test (Mann-Whitney test) for two groups or the one-way ANOVA test (Kruskal-Wallis test) for three groups using GraphPad Prism 5.0 software (GraphPad Software, Inc., San Diego, CA, USA). $P<0.05$ was considered significant.

\section{Results}

Influence of oxygen on the physiology of L. panis PM1

The rates of growth during the first 24 hours of culture were similar between aerobic and microaerobic L. panis PM1; however, the aerobically cultured L. panis PM1 entered stationary phase earlier than the microaerobic culture (Figures $1 \mathrm{a}$ and $\mathrm{b}$ ). This early entry into stationary phase was associated with a halt in production of end-products, but not with glucose depletion (as approximately $30 \mathrm{mM}$ glucose remained after 24 hours) (Figure 1a), indicating that glucose concentration was not a critical cause of the cellular growth interruption. Unlike aerobically cultured samples, the microaerobic cultures consumed all available glucose $(55 \mathrm{mM})$ within 48 hours and produced nearlyequimolar amounts of lactic acid and ethanol (Figure 1b), revealing a typical heterolactic fermentation of glucose through the 6-PG/PK pathway. Also, the cells grown under microaerobic conditions were observed to consume lactic acid during stationary phase, reducing the concentration of lactate from $53 \mathrm{mM}$ to $33 \mathrm{mM}$. In contrast, aerobic cultures did not utilize lactic acid after cessation of glucose consumption (Figure 1a). Furthermore, the ratio of ethanol production to glucose consumption (11:26 mM) was less during aerobic culture than during microaerobic culture $(55: 55 \mathrm{mM})$. These results indicated that, under aerobic conditions, an alternate metabolic route reoxidized NADH through the 6-PG/PK pathway while not forming ethanol.

\section{Production of $\mathrm{H}_{2} \mathrm{O}_{2}$ by aerobic culture and its effects on bacterial growth}

Aerobic culture resulted in the production of ten-fold higher concentrations of $\mathrm{H}_{2} \mathrm{O}_{2}$ than during microaerobic culture. Rapid accumulation of $\mathrm{H}_{2} \mathrm{O}_{2}$, reaching approximate $100 \mu \mathrm{M}$, was achieved in the first 24 hours of aerobic culture (Figure 2a). The concentration of $\mathrm{H}_{2} \mathrm{O}_{2}$ necessary to completely inhibit the growth of $L$. panis

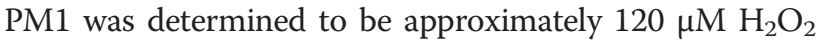
(Figure 2b). Accumulation of $\mathrm{H}_{2} \mathrm{O}_{2}$ reached close to this inhibitory concentration level within 24 hours of aerobic culture. Concurrently, a reduction of cell density was observed after 24 hours aerobic culture (Figure 1b). This data, therefore, indicated a clear association between $\mathrm{H}_{2} \mathrm{O}_{2}$ produced under aerobic conditions and the early entrance of $L$. panis PM1 into stationary phase.

\section{Specific activities of NADH oxidase and NADH peroxidase}

The whole genome data of L. panis PM1 (unpublished draft data) revealed only candidate genes for NADH oxidase and NADH peroxidase; whereas, other protective enzyme genes that might respond to the toxic effects caused by oxygen were not detected. The expression levels of these two genes were compared under aerobic and microaerobic conditions by qRT-PCR. It was determined that 

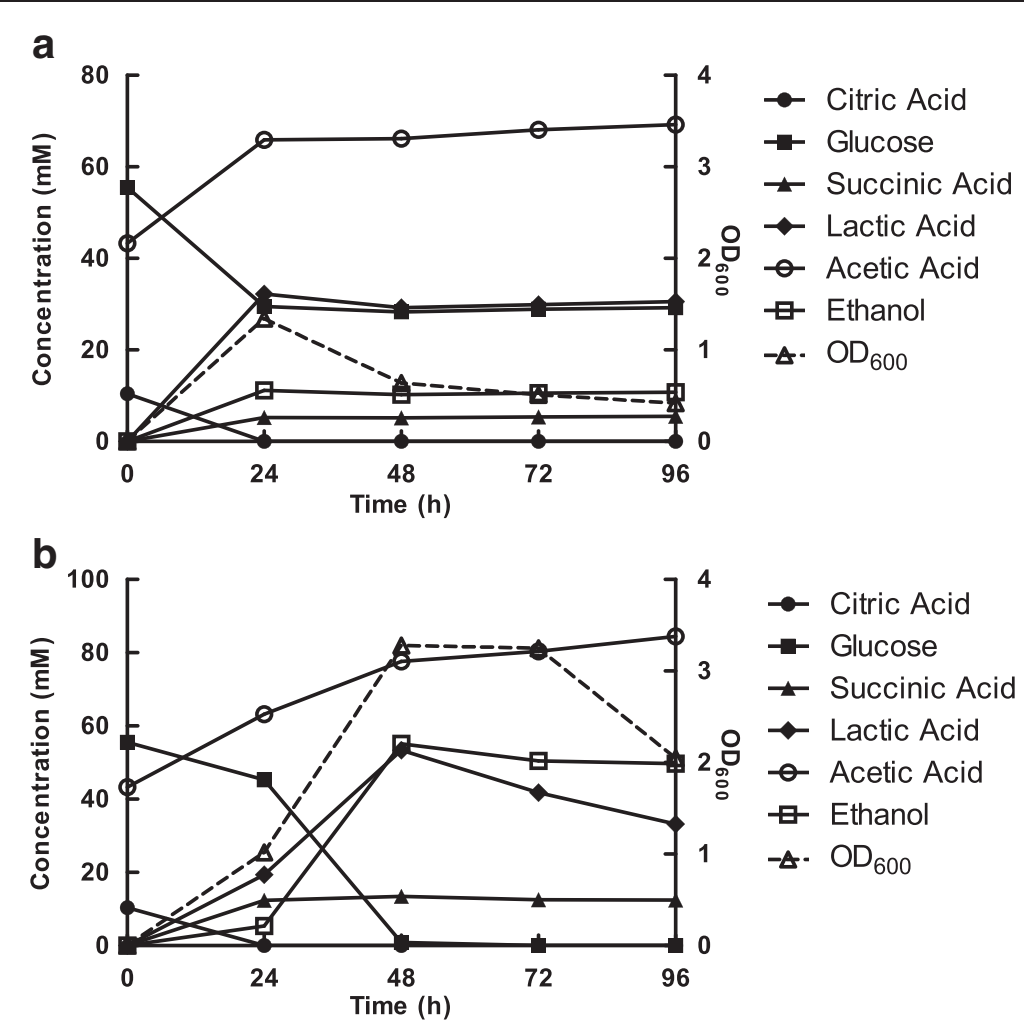

Figure 1 Effect of oxygen and time on growth and end-product formation in L. panis PM1. Growth response $\left(\mathrm{OD}_{600}\right)$ and end-product formation of L. panis PM1 cultivated in mMRS under aerobic (a) and microaerobic (b) conditions. Samples for cell density and HPLC analysis were withdrawn from the cultures after 24, 48, 72 and 96 hours.

$n o x$ (NADH oxidase gene) and $n p x$ (NADH peroxidase gene) were expressed at similar levels under both culture conditions (Table 2) even though L. panis PM1 was shown to produce lethal levels of hydrogen peroxide under aerobic, but not microaerobic, conditions. The levels of activity of NADH oxidase and NADH peroxidase were measured from the cells grown under microaerobic and aerobic culture conditions. The specific activity of NADH oxidase was comparable $(P>0.1)$ under both aerobic and microaerobic cultures (Table 2). Interestingly, the activities of NADH oxidase were dependent on availability of oxygen in the respective assay reactions. When the specific activities of NADH oxidase were compared between aerated and non-aerated assay conditions, significant differences were observed $(P<0.05)$. Higher activities of NADH oxidase were observed in aerated assay than non-aerated assay for both aerobically- and microaerobically-grown cultures (158.8 \pm 7.6 vs. $92.5 \pm 2.2$ and $144.0 \pm 2.0$ vs. $103.1 \pm 5.6$ units $/ \mathrm{mg}$, respectively). In contrast to NADH oxidase, NADH peroxidase activity was only detected in aerobic cultures. Enzyme assay conditions significantly $(P<0.05)$ affected the levels of activity of NADH peroxidase in the opposite direction of NADH oxidase; higher enzyme activity was observed under non-aerated assay conditions (148.3 \pm 9.7 vs. $197.3 \pm 1.7$ units/mg) (Table 2).

\section{Role of oxygen in oxidative stress}

Oxygen availability in the culture media directly affected the coupled NADH oxidase - NADH peroxidase system of L. panis PM1, controlling the accumulation of $\mathrm{H}_{2} \mathrm{O}_{2}$ under aerobic conditions. When $L$. panis PM1 was cultured in 15-ml conical tubes containing 9, 6, and $3 \mathrm{ml}$ mMRS under aerobic conditions (in order to incrementally-increase oxygen availability in the aerobic cultures), the $\mathrm{H}_{2} \mathrm{O}_{2}$ accumulation was greatest and most rapid in the 3-ml culture, reaching a maximal value by 12 hours in all samples (Figure 3). The $\mathrm{H}_{2} \mathrm{O}_{2}$ concentration decreased after 12 hours in all samples; however, the degree of $\mathrm{H}_{2} \mathrm{O}_{2}$ decomposition occurred in proportion to oxygen availability in the culture media (63\% in the $3-\mathrm{ml}$ culture, $33 \%$ in the 6-ml culture, and $13 \%$ in the $9-\mathrm{ml}$ culture). The final amount of cell growth was in accordance with the amount of $\mathrm{H}_{2} \mathrm{O}_{2}$ accumulated in the culture media until 12 hours (Table 3 and Figure 3). NADH oxidase activity was constitutively-expressed during the early stages of cell culture, and high NADH oxidase activities were determined in 


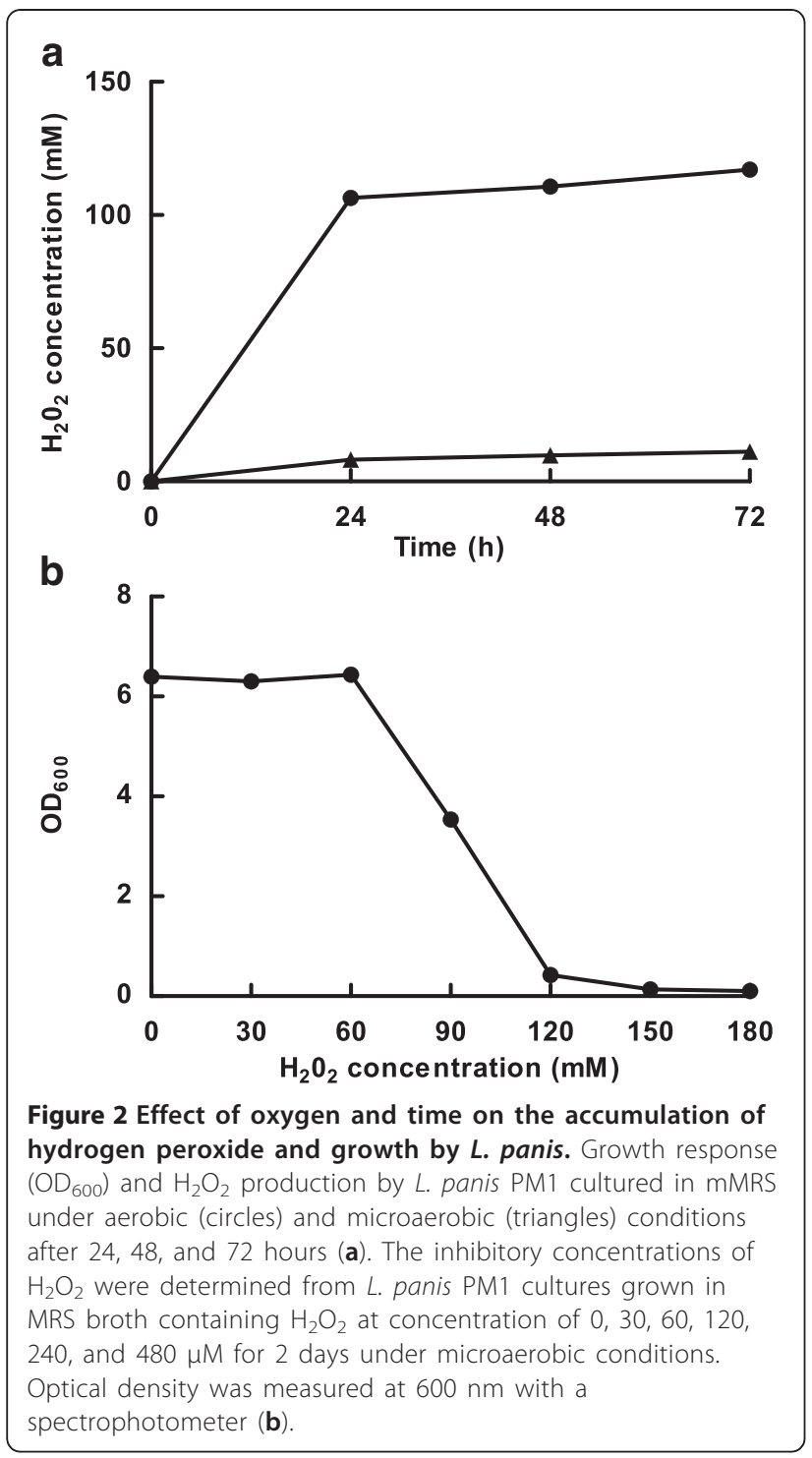

the all 6-hour aerobic cultures (approximately 100 units/mg). The activity of this enzyme increased in a time-dependent manner until after 24 hours of culture. The specific activities of NADH oxidase did not show significant differences in the three aerobic culture conditions $(P>0.1)$. In contrast to $\mathrm{NADH}$ oxidase, NADH peroxidase specific activity was only observed in the 3-ml 24-hour culture (Table 3). This data clearly demonstrated that NADH peroxidase activity was induced according to oxygen availability that also elevated the production of $\mathrm{H}_{2} \mathrm{O}_{2}$ by NADH oxidase.

\section{The change of NADH flux by NADH oxidase}

Oxygen was a preferred electron acceptor for glycerol or citric acid and changed the flux of NADH for reoxidation in $L$. panis PM1. Inhibitory levels of $\mathrm{H}_{2} \mathrm{O}_{2}$ were accumulated following 24 hour culture of $L$. panis PM1 in mMRS containing either citric acid $(24 \mathrm{mM})$ or glycerol $(160 \mathrm{mM})$ as electron acceptors under aerobic conditions (124 and $120 \mu \mathrm{M} \mathrm{H} \mathrm{H}_{2} \mathrm{O}_{2}$, respectively). The consumption of glucose (11 and $27 \mathrm{mM}$ in citric acid and glycerol media, respectively) and production of ethanol (4 and $6 \mathrm{mM}$ in citric acid and glycerol media, respectively) were suppressed similar to that observed in aerobic cultures lacking additional electron accepters (Figure 4). In addition, little citric acid (7 $\mathrm{mM})$ or glycerol $(13 \mathrm{mM})$ was consumed. The amount of lactic acid produced correlated only with the amount of glucose utilized. Considering the amount of citric acid or glycerol consumed and acetic acid produced (28 and $39 \mathrm{mM}$, respectively) in the culture media, it appeared that citric acid and glycerol contributed only slightly to an increase in acetic acid production and utilization for NADH recycling.

\section{Discussion}

We previously reported the aerotolerant nature of $L$. panis PM1 and its ability to use glycerol as the means of $\mathrm{NADH}$ recycling in the absence of oxygen (Khan et al. 2013). However, the presence of oxygen prevented 1,3PDO formation and thus markedly-affected NADH recycling in this strain. In this study, the influence of

Table 2 The specific activities of NADH oxidase and NADH peroxidase of $L$. panis PM1

\begin{tabular}{|c|c|c|c|c|c|}
\hline \multirow[t]{2}{*}{ Enzyme sources $^{a}$} & \multirow{2}{*}{$\begin{array}{l}\text { Enzyme assay } \\
\text { conditions }\end{array}$} & \multicolumn{2}{|c|}{ Enzyme activity $^{b}$} & \multicolumn{2}{|c|}{ Relative gene expression level $^{j}$} \\
\hline & & NADH oxidase & NADH peroxidase & nox & $n p x$ \\
\hline Aerobic culture & Aerated condition & $158.8 \pm 7.6^{d}$ & $148.3 \pm 9.7^{h}$ & $1.50 \pm 0.30$ & $1.16 \pm 0.28$ \\
\hline Microaerobic culture & & $144.0 \pm 2.0^{e}$ & N.D ${ }^{c}$ & $1.00 \pm 0.22$ & $1.00 \pm 0.10$ \\
\hline Aerobic culture & Non-aerated condition & $92.5 \pm 2.2^{f}$ & $197.3 \pm 1.7^{i}$ & & \\
\hline Microaerobic culture & & $103.1 \pm 5.6^{g}$ & N.D ${ }^{c}$ & & \\
\hline
\end{tabular}

${ }^{a}$. Lactobacillus panis PM1 was cultured in mMRS for 24 hours under aerobic or microaerobic conditions for enzyme assays. ${ }^{\mathrm{b}}$. Values represent specific activities (unit/mg protein). One unit is defined as one micromole of $\mathrm{H}_{2} \mathrm{O}_{2}$ generated (for NADH oxidase) or decomposed (for NADH peroxidase) per minute. '. Minus values where $\mathrm{H}_{2} \mathrm{O}_{2}$ generating ability was higher than $\mathrm{H}_{2} \mathrm{O}_{2}$ decomposing ability are defined as non-detectable (N.D) in NADH peroxidase assay. ${ }^{d}$. Significantly different to $\mathrm{f}, P<0.05$. ${ }^{\mathrm{e}}$. Significantly different to $\mathrm{g}, P<0.05$. ${ }^{\mathrm{h}}$. Significantly different to $\mathrm{i}, P<0.05 .{ }^{\mathrm{j}}$. Microaerobic culture was used for control sample for relative gene expression by qRT-PCR. 


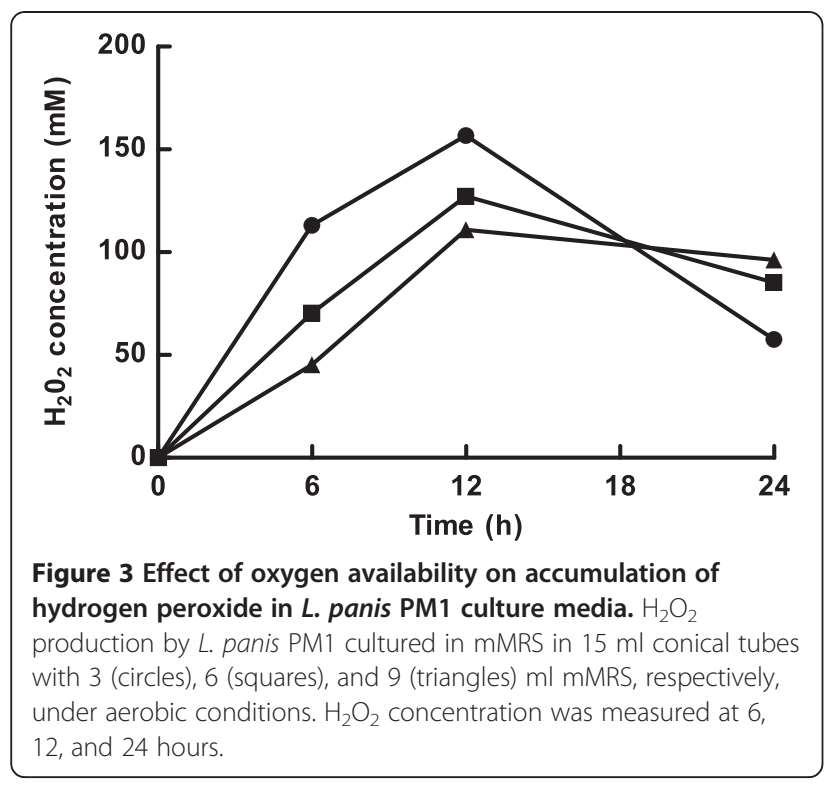

oxygen on NADH recycling system and the oxidative stress resistance mechanism in its aerotolerance was investigated. Moreover, the metabolic profile was further investigated to understand how oxidative stress resistance mechanisms of $L$. panis PM1 influenced the profile of metabolic end-products.

During aerobic culture, L. panis PM1 prematurely entered into a stationary phase without depleting glucose (Figure 1a). This early entry into stationary phase was also associated with a ten-fold higher accumulation of $\mathrm{H}_{2} \mathrm{O}_{2}$ compared with microaerobic culture (Figure 2a). Therefore, the accumulation of $\mathrm{H}_{2} \mathrm{O}_{2}$ in aerobic culture was an apparent reason for the early cessation of growth. Anaerobic metabolism theoretically makes one ethanol per every glucose consumed, but the presence of oxygen altered this pattern to less than 1:1 ratio. These observations suggested that $\mathrm{H}_{2} \mathrm{O}_{2}$ could be a main end-product of an alternate pathway for $\mathrm{NADH}$ recycling under aerobic conditions, and that this could compete with $\mathrm{NAD}^{+}$-regeneration through ethanol production.

Table 3 The result of cell growth and specific activities of NADH oxidase and NADH peroxidase according to oxygen availability

\begin{tabular}{lccc}
\hline Culture Vol. & $\mathbf{3} \mathbf{~ m l}$ & $\mathbf{6} \mathbf{~ m l}$ & $\mathbf{9} \mathbf{~ m l}$ \\
\hline${\text { Cell Growth }\left(\mathrm{OD}_{600}\right)^{\text {a }}}$ & 0.59 & 1.18 & 2.26 \\
NADH oxidase activity $^{\mathrm{b}}$ & $177.6 \pm 3.0$ & $193.2 \pm 2.5$ & $192.8 \pm 5.7$ \\
NADH peroxidase activity $^{\mathrm{b}}$ & $120.1 \pm 12.51$ & N.D & N.D
\end{tabular}

${ }^{a}$. Lactobacillus panis PM1 was cultured in mMRS under aerobic conditions, and samples for cell growth and enzyme assays withdrawn from the cultures after 24 hours. ${ }^{b}$. Values represent specific activities (unit/mg protein). One unit is defined as one micromole of $\mathrm{H}_{2} \mathrm{O}_{2}$ generated (for NADH oxidase) or decomposed (for NADH peroxidase) per minute. NADH oxidase and NADH peroxidase assays were carried out under aerated and non-aerated conditions, respectively.
The production of $\mathrm{H}_{2} \mathrm{O}_{2}$ by LAB grown under aerobic conditions is commonly the result of flavoprotein oxidases, including NADH oxidase, pyruvate oxidase, $\alpha-$ glycerophosphate oxidase, and superoxide dismutase (Condon 1987). However, candidate genes for these enzymes were not found in the draft genome data of L. panis PM1, with the exception of $\mathrm{NADH}$ oxidase. Pyruvate oxidase has been documented in a few species of lactobacilli and is known to convert pyruvate to $\mathrm{CO}_{2}$ and acetyl phosphate, along with the formation $\mathrm{H}_{2} \mathrm{O}_{2}$ (Condon 1987). Pyruvate oxidase has its highest activity during the early stationary phase of growth and is induced and repressed by oxygen and glucose, respectively, in L. plantarum (Saxena et al. 2009; Veiga-da-Cunha and Foster 1992). However, the presence of pyruvate oxidase does not adequately explain the early entry into stationary phase observed during the aerobic culture of $L$. panis PM1. Our results showed that most of pyruvate produced during glucose consumption was used to produce lactate in aerobic culture (Figure 1a), indicating that pyruvate oxidase apparently removed little pyruvate from this pathway. NADH oxidase is the most common enzyme responsible for the production of $\mathrm{H}_{2} \mathrm{O}_{2}$ from oxygen and is highly-active in LAB (Condon 1987; Higuchi et al. 2000; Tachon et al. 2011). LAB are known to possess either a NADH: $\mathrm{H}_{2} \mathrm{O}_{2}$ or a NADH: $\mathrm{H}_{2} \mathrm{O}$ oxidase, or sometimes both (Condon 1987; Higuchi et al. 2000). Final products of the reaction of NADH oxidase include either $\mathrm{NAD}^{+}$ and $\mathrm{H}_{2} \mathrm{O}_{2}$, or $\mathrm{NAD}^{+}$and $\mathrm{H}_{2} \mathrm{O}$, depending on whether two- or four-electrons are transferred by NADH: $\mathrm{H}_{2} \mathrm{O}_{2}$ oxidase or NADH: $\mathrm{H}_{2} \mathrm{O}$ oxidase (Condon 1987; Higuchi et al. 2000; Miyoshi et al. 2003). Our results showed that the crude extract from L. panis PM1 cultured under aerobic and microaerobic conditions could directly produce $\mathrm{H}_{2} \mathrm{O}_{2}$ using oxygen as a substrate, and the activity of the enzyme was found to increase with the addition of $\mathrm{FAD}^{+}$ as well as aeration of the assay mixture (approximately 1.5 fold). These results indicated that the NADH oxidase in L. panis $\mathrm{PM} 1$ was a NADH: $\mathrm{H}_{2} \mathrm{O}_{2}$ oxidase and a flavoprotein-like NADH oxidase, as seen in other grampositive bacteria (Komagata 1996; Marty-Teysset et al. 2000; Tachon et al. 2011).

Most $\mathrm{LAB}$ can respond (and protect themselves) to high concentrations of $\mathrm{H}_{2} \mathrm{O}_{2}$ produced through their oxidase enzymes during sugar fermentation (Higuchi et al. 2000). In fact, most LAB possess NADH peroxidase or pseudocatalase, and superoxide dismutase exists in some LAB (Condon 1987). These enzymes can enable LAB to overcome otherwise-lethal concentrations of hydrogen peroxide. The annotation data of the $L$. panis PM1 genome sequence and the results of the enzyme assays of NADH oxidase and NADH peroxidase suggest that these enzymes are main factors in oxidative stress resistance. The levels of accumulated $\mathrm{H}_{2} \mathrm{O}_{2}$ in the culture media could be 


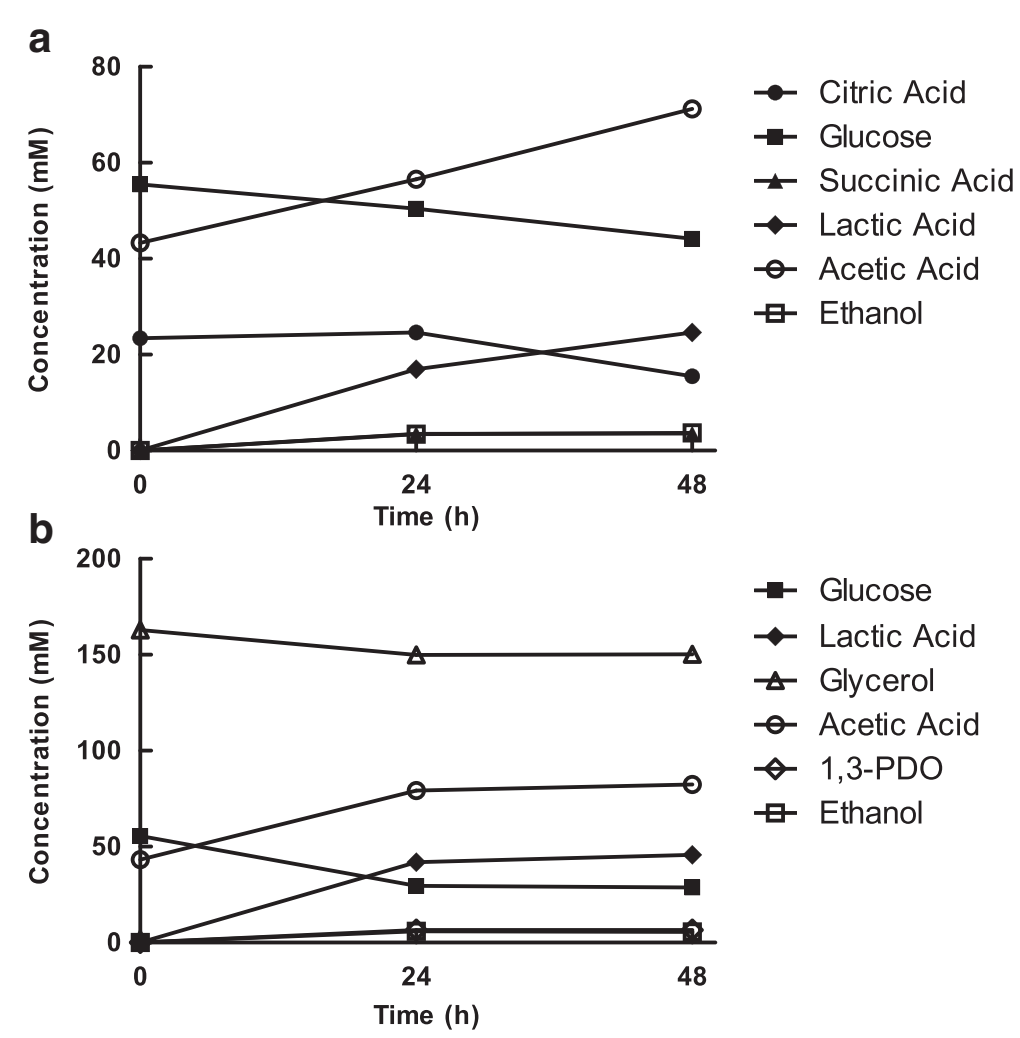

Figure 4 Effect of external electron acceptors on end-product formation by L. panis PM1. End-product formation by L. panis PM1 cultured in mMRS containing either $24 \mathrm{mM}$ citric acid (a) or $160 \mathrm{mM}$ glycerol (b) as external electron acceptor under aerobic conditions. Samples for HPLC analysis were withdrawn from the cultures after 24 and 48 hours.

accounted for by the differences in the activities of NADH peoxidase and NADH oxidase. Our qRT-PCR analyses showed that oxygen did not regulate nox and $n p x$ at the transcriptional-level, and mainly affected enzyme activities in L. panis PM1 (Table 2). While transcription levels were similar, activity assays exhibited that NADH peroxidase was positively-activated by oxygen but required a long induction time to express activity contrary to NADH oxidase. The oxygen-availability analyses indicated that higher oxygen availability in the 3-ml culture could provide higher amounts of substrate (oxygen) for NADH oxidase, resulting in greater accumulation of $\mathrm{H}_{2} \mathrm{O}_{2}$ in the first 12 hours. In the subsequent 12 hours, the accumulated $\mathrm{H}_{2} \mathrm{O}_{2}$ was decomposed by NADH peroxidase activity. The degree of degradation of $\mathrm{H}_{2} \mathrm{O}_{2}$ was dependent on NADH peroxidase activity, and the amount of activity was in proportion with oxygen availability (Figure 3 and Table 3). Therefore, we concluded that a coupled NADH oxidase - NADH peroxidase system, regulated by oxygen availability, was a key oxidative stress resistance mechanism in L. panis PM1.

Accumulation of $\mathrm{H}_{2} \mathrm{O}_{2}$ by NADH oxidase has been reported in group I homofermentative lactobacilli, like L. delbrueckii, where approximate $97 \%$ of NADH was reoxidized by lactate dehydrogenase and NADH oxidase accounted for only 3\% of NADH reoxidation (Marty-Teysset et al. 2000). Thus, NADH recycling in group I LAB depends on a pyruvate supply from glycolysis, rather than oxygen. Unlike homofermentative lactobacilli, the presence of electron acceptors, such as oxygen, citric acid, or glycerol, directly influenced the flux of NADH reoxidation in L. panis PM1. In our other studies, when L. panis PM1 was cultured in mMRS containing citric acid $(24 \mathrm{mM})$ and glycerol $(150 \mathrm{mM})$ under microaerobic conditions, the major changes in end-product formation included a decrease in ethanol, an increase in acetic acid, and the production of succinic acid $(19 \mathrm{mM})$ and 1,3-PDO $(88 \mathrm{mM})$, respectively (unpublished data). The results of HPLC analyses in the present study showed that aerobic conditions negatively-affected the production of ethanol relative to glucose consumption, regardless of the presence of electron acceptors (Figures 1a and 4). Also, when L. panis PM1 was cultured under aerobic conditions in mMRS containing citric acid and glycerol, oxygen was used as the preferred electron acceptor, resulting in a shift of NADH flux along with a significant decrease of the production of succinic acid $(4 \mathrm{mM})$ and 1,3-PDO (7 mM) (Figure 4). This data indicated that the activity of NADH 
oxidase was a key mechanism for the reoxidation of $\mathrm{NADH}$ during growth in aerobic culture.

In addition to oxidative stress responses, NADH oxidase can also help $L$. panis PM1 use oxygen during energy metabolism, directly. That is, the shift of NADH recycling with molecular oxygen redirected acetyl phosphate, which normally would be used to produce ethanol, to the formation of acetic acid. This acetic acid production via acetate kinase can stoichiometrically generate ATP (Condon 1987). Thus, $\mathrm{O}_{2}$-directed NADH recycling should be advantageous with respect to energy metabolism. However, regeneration of $\mathrm{NAD}^{+}$via NADH oxidase in L. panis PM1 led to overproduction of $\mathrm{H}_{2} \mathrm{O}_{2}$ with subsequent negative effects on growth and end-product formation. Our findings indicate that varied oxygen availabilities of culture environments would greatly affect energy metabolism as well as oxidative stress of $L$. panis PM1. The formation of 1,3-PDO is a main route for NADH reoxidation in the presence of glycerol under anaerobic conditions; whereas, under aerobic conditions, NADH recycling largely occurs through NADH oxidase activity. The present study indicates that energy metabolism via the NADH oxidase system explains why L. panis PM1 fails to produce 1,3-PDO under aerobic conditions.

\section{Competing interest}

The authors declare that they have no competing interest.

\section{Acknowledgements}

The authors acknowledge the Saskatchewan Agriculture Development Fund and Agricultural Bioproducts Innovation Program of Agriculture and AgriFood Canada for supporting this research.

Received: 23 January 2013 Accepted: 24 January 2013

Published: 31 January 2013

\section{References}

An H, Zhai Z, Yin S, Luo Y, Han B, Hao Y (2011) Coexpression of the superoxide dismutase and the catalase provides remarkable oxidative stress resistance in Lactobacillus rhamnosus. J Agric Food Chem 59(8):3851-3856

An H, Zhou H, Huang Y, Wang G, Luan C, Mou J, Luo Y, Hao Y (2010) High-level expression of heme-dependent catalase gene katA from Lactobacillus Sakei protects Lactobacillus rhamnosus from oxidative stress. Mol Biotechnol 45 (2):155-160

Anders RF, Hogg DM, Jago GR (1970) Formation of hydrogen peroxide by group $\mathrm{N}$ streptococci and its effect on their growth and metabolism. Appl Microbiol 19(4):608-612

Chen K-H, McFeeters RF (1986) Utilization of electron acceptors for anaerobic metabolism by Lactobacillus plantarum. Enzymes and intermediates in the utilization of citrate. Food microbiology 3:83-92

Condon S (1987) Responses of lactic acid bacteria to oxyben. FEMS Microbiol Rev 46:269-280

Farr SB, Kogoma T (1991) Oxidative stress responses in Escherichia coli and Salmonella typhimurium. Microbiol Rev 55(4):561-585

Higuchi M, Yamamoto Y, Kamio Y (2000) Molecular biology of oxygen tolerance in lactic acid bacteria: Functions of $\mathrm{NADH}$ oxidases and Dpr in oxidative stress. J Biosci Bioeng 90(5):484-493

Jansch A, Freiding S, Behr J, Vogel RF (2011) Contribution of the NADH-oxidase (Nox) to the aerobic life of Lactobacillus sanfranciscensis DSM20451T. Food microbiology 28(1):29-37

Kandler O (1983) Carbohydrate metabolism in lactic acid bacteria. Antonie van Leeuwenhoek 49(3):209-224

Khan NH, Kang TS, Grahame DA, Haakensen MC, Ratanapariyanuch K, Reaney MJ, Korber DR, Tanaka T (2013) Isolation and characterization of novel 1,3 propanediol-producing Lactobacillus panis PM1 from bioethanol thin stillage. Appl Microbiol Biotechnol 97(1):417-428

Komagata MSK (1996) Aerobic growth of and activities of NADH oxidase and NADH peroxidase in lactic acid bacteria. J Ferment Bioeng 82(3):210-216

Livak KJ, Schmittgen TD (2001) Analysis of relative gene expression data using real-time quantitative PCR and the 2(-Delta Delta C(T)) Method. Methods (San Diego, Calif 25(4):402-408

Luthi-Peng Q, Dileme FB, Puhan Z (2002) Effect of glucose on glycerol bioconversion by Lactobacillus reuteri. Appl Microbiol Biotechnol 59(2-3):289296

Marty-Teysset C, de la Torre F, Garel J (2000) Increased production of hydrogen peroxide by Lactobacillus delbrueckii subsp. bulgaricus upon aeration: involvement of an $\mathrm{NADH}$ oxidase in oxidative stress. Appl Environ Microbiol 66(1):262-267

McFeeters RF, Chen K-H (1986) Utilization of electron acceptors for anaerobic mannitol metabolism by Lactobacillus plantarum, Compounds which serve as electron acceptors. Food microbiology 3:73-81

Miyoshi A, Rochat T, Gratadoux JJ, Le Loir Y, Oliveira SC, Langella P, Azevedo V (2003) Oxidative stress in Lactococcus lactis. Genet Mol Res 2(4):348-359

Oh ET, So JS (2003) A rapid method for RNA preparation from Gram-positive bacteria. J Microbiol Methods 52(3):395-398

Pedersen C, Jonsson H, Lindberg JE, Roos S (2004) Microbiological characterization of wet wheat distillers' grain, with focus on isolation of lactobacilli with potential as probiotics. Appl Environ Microbiol 70(3):1522-1527

Saxena RK, Anand P, Saran S, Isar J (2009) Microbial production of 1,3propanediol: Recent developments and emerging opportunities. Biotechnol Adv 27(6):895-913

Sedewitz B, Schleifer KH, Gotz F (1984) Purification and biochemical characterization of pyruvate oxidase from Lactobacillus plantarum. J Bacteriol 160(1):273-278

Tachon S, Chambellon E, Yvon M (2011) Identification of a conserved sequence in flavoproteins essential for the correct conformation and activity of the NADH oxidase NoxE of Lactococcus lactis. J Bacteriology 193(12):3000-3008

Talarico TL, Axelsson LT, Novotny J, Fiuzat M, Dobrogosz WJ (1990) Utilization of Glycerol as a Hydrogen Acceptor by Lactobacillus reuteri: Purification of 1,3Propanediol:NAD Oxidoreductase. Appl Environ Microbiol 56(4):943-948

Veiga-da-Cunha M, Foster MA (1992) 1,3-Propanediol:NAD + oxidoreductases of Lactobacillus brevis and Lactobacillus buchneri. Appl Environ Microbiol 58 (6):2005-2010

doi:10.1186/2191-0855-3-10

Cite this article as: Kang et al:: Influence of oxygen on NADH recycling and oxidative stress resistance systems in Lactobacillus panis PM1. AMB Express 2013 3:10

\section{Submit your manuscript to a SpringerOpen ${ }^{\odot}$ journal and benefit from:}

- Convenient online submission

- Rigorous peer review

- Immediate publication on acceptance

- Open access: articles freely available online

- High visibility within the field

- Retaining the copyright to your article

Submit your next manuscript at $>$ springeropen.com 